\title{
The Effect of Laparoscopic Ovarian Drilling on Anti-Müllerian Hormone, LH/FSH Ratio and Inhibin B
}

\author{
Original \\ Ezeldin Mohamed ${ }^{1}$, Magd El Din Mohamed ${ }^{1}$, Mohamed Taha', Iman Abozeid ${ }^{2}$ \\ Article \\ ${ }^{1}$ Department of Obstetrics and Gynaecology, Faculty of Medicine, Ain-Shams University \\ ${ }^{2}$ General Organization For Teaching Hospitals and Institutes, El-Galaa Maternity Teaching \\ Hospital, Cairo, Egypt
}

\begin{abstract}
Aim: This study aimed to compare AMH to other parameters of ovarian reserve (OR) in evaluating the effect of laparoscopic ovarian drilling (LOD) on OR in treatment of PCO.

Results: The mean AMH level before the operation was $6.9 \pm 1.4 \mathrm{ng} / \mathrm{ml}$ and $8.2 \pm 1.4 \mathrm{ng} / \mathrm{ml}$ for the patients who got pregnant and those who did not get pregnant respectively. While the mean AMH level after 3 months of the operation was $5.1 \pm 1.1 \mathrm{ng} / \mathrm{ml}$ and $6.3 \pm 1.4 \mathrm{ng} / \mathrm{ml}$ for the patients who got pregnant and those who did not get pregnant respectively. The mean LH/FSH ratio before the operation was $2.04 \pm 0.5$ and $3.02 \pm 0.6$ for the patients who got pregnant and those who did not get pregnant respectively. While the mean LH/FSH ratio after 3 months of the operation was $1.15 \pm 0.2$ and $1.93 \pm 0.6$ for the patients who got pregnant and those who did not get pregnant respectively. The mean inhibin B level before the operation was $52.5 \pm 2.2 \mathrm{pg} / \mathrm{ml}$ and $52.6 \pm 3.9 \mathrm{pg} / \mathrm{ml}$ for the patients who got pregnant and those who did not get pregnant respectively. While the mean inhibin B level after 3 months of the operation was $48.3 \pm 2.1 \mathrm{pg} / \mathrm{ml}$ and $49.1 \pm 3.6 \mathrm{pg} / \mathrm{ml}$ for the patients who got pregnant and those who did not get pregnant respectively.

Conclusion: Pregnancy rates were significantly related to the preoperative LH/FSH ratio and AMH levels when comparing the cases that got pregnant with the cases who did not conceive postoperatively in patients of polycystic ovary syndrome (PCOS), whereas preoperative Inhibin B level had no relation to pregnancy rates.
\end{abstract}

Key Words: AMH, inhibin B, ovarian drilling, PCOS

Received: 28 September 2019, Accepted: 28 September 2019

Corresponding Author: Ezeldin Mohamed, Department of Obstetrics and Gynaecology, Faculty of Medicine, Ain-Shams University, Cairo, Egypt, Tel.: 01069491030, E-mail: ezeldinmohamed4@gmail.com

ISSN: 2090-7265, May 2021, Vol.11, No. 2

\section{INTRODUCTION}

PCOS is highly prevalent endocrinopathy in women in the childbearing period. PCOS is associated with reproductive and metabolic alterations, and constitutes the most common cause of anovulation in women ${ }^{[1]}$.

The mammalian ovary has a finite number of oocytes that form during fetal development. The size of the primordial follicle pool (i.e., the ovarian reserve) declines with age and is likely a key determinant of the reproductive lifespan ${ }^{[2]}$. Patients with PCOS have a larger follicle pool than normo-ovulatory women. With advancing age, the follicle pool decreases in both patients with PCOS and normo-ovulatory women. However, as patients with PCOS have a greater initial pool of follicles, their ovarian reserve is unlikely to undergo rapid depletion with age ${ }^{[3]}$.

Anti-Müllerian hormone (AMH) also called egg timer is a transforming growth factor $\beta$ (TGF- $\beta$ ) family member and is produced by the granulosa cells of primary to small antral follicles and it is connected to the number of small antral follicles. AMH is the only ovarian reserve marker that is absolutely menstrual cycle independent and it is not affected by oral contraception and GnRH agonists ${ }^{[4]}$.

Serum AMH has been evaluated as an additional diagnostic marker for $\mathrm{PCOS}^{[5]}$. Based on its activities, AMH has been proposed to be involved in the pathophysiology of $\mathrm{PCOS}^{[6]}$.

Medical treatment through induction of ovulation is the standard first line of management in infertile women with PCOD. Surgical treatment of PCOS started in 1935 by Stein and Leventhal by wedge resection of the ovaries. Laparoscopic ovarian surgery is indicated in cases of clomiphene citrate resistance or failure ${ }^{[7]}$. Laparoscopic ovarian surgery could be second line therapy for women with PCOS, who are clomiphene citrate resistant, with anovulatory infertility and no other infertility factors ${ }^{[8]}$.

The mechanism of action of LOD is largely unexplained. In particular, it is not known whether LOD exerts its action through a direct effect on the ovary or through a systemic endocrine mechanism. One of the theories that explain the effect of LOD is the higher ovarian reserve presents 
in patients with PCO. This proposed mechanism of exaggerated ovarian activity (at supraphysiological state) can be reduced to the physiological level by destruction or removal of some part of the ovary retaining the ovarian activity to physiological state ${ }^{[9]}$.

Several lines of evidence demonstrate a close association between changes in serum AMH concentrations and improvement in PCOS manifestations in response to treatment, providing further support to the notion that $\mathrm{AMH}$ is causally related to PCOS pathophysiology. However, it is unknown whether the decrease seen in AMH following LOD is simply reflective of the destruction of AMHproducing granulosa cells, or is actually mechanistically related to the clinical improvement. The predictive ability of pre-operative $\mathrm{AMH}$ concentration for treatment success would argue for the latter. It is possible that decreased local ovarian production of AMH following LOD may lead to increased follicular responsiveness to FSH and release from the follicular arrest ${ }^{[10]}$.

\section{AIM OF THE WORK}

It is a study to compare AMH to other parameters of ovarian reserve (OR) in evaluating the effect of laparoscopic ovarian drilling (LOD) on OR in treatment of PCO in terms of change of level after the drilling and the pregnancy rate.

\section{PATIENTS AND METHODS}

Study type: This is a comparative prospective clinical trial study.

Study population : Forty eight patients with PCO were included in the study. The included women in this study were with either primary or secondary infertility, with mean age $31.2 \pm 4.04$ years, mean BMI $30.7 \pm 3.75\left(\mathrm{~kg} / \mathrm{m}^{2}\right)$ and mean infertility years $5.02 \pm 2.3$ years.

Patients with PCOS were diagnosed as having PCOS if they were found to have two of the following three criteria: Chronic anovulation or oligovulation after excluding secondary causes, Clinical or biochemical hyperandrogenism and polycystic ovaries on ultrasound according to Balen et al criteria ${ }^{[1 ; 12]}$.

On the other hand, the exclusion criteria were any patient who received any medication within the last 3 months including but not limited to corticosteroids, ovulation inducing agents, hormonal contraceptive methods. Any patient diagnosed with Thyroid disease, Cushing's syndrome, Adult onset congenital adrenal hyperplasia or Androgen-secreting ovarian or adrenal tumors or hyperprolactinemia were also excluded.

Serum AMH was $8.07 \pm 1.49 \mathrm{ng} / \mathrm{ml}, \mathrm{LH} / \mathrm{FSH}$ ratio was $2.8 \pm 0.7$ and inhibin B was $52.5 \pm 3.68 \mathrm{pg} / \mathrm{ml}$.
After enrollment in our study, these patients were found to comply with phenotype A of PCOS according to the classification of Carmina (hyperandrogenemia, anovulation, PCO morphology (PCOM), increased AMH and metabolic issues) $)^{[13]}$.

\section{Sample size calculations :}

The sample size of at least 33 patients was estimated to detect a difference of $3 \mathrm{ng} / \mathrm{ml}$ of AMH after drilling with standard deviation SD of $6 \mathrm{ng} / \mathrm{ml}$ given an alpha error of 0.05 and power of $80 \%$ according to Elmashad et $a{ }^{[14]}$.

\section{Ethics statement :}

The study was approved by the local Ethics Committee. Informed consent was taken from participants includes information about risks and benefits out of the research, and also that participating women's right to withdraw from the study without being adversely impacted. This study was conducted in Ain Shams University Maternity Hospital. The patients were recruited from the gynaecologic outpatient clinic of Ain Shams university hospital from January 2014 to December 2017 i.e. about four years.

\section{Study methods}

For all patients a complete history was taken and a physical examination including measurement of body mass index (BMI) was done. Ultrasound examination to detect polycystic ovaries was done to confirm the diagnosis of polycystic ovaries according to Balen et al criteria ${ }^{[11]}$.

A single venous blood sample was drawn from the PCOS patients in the second day of the cycle for measurement of LH/FSH ratio, serum Inhibin B and serum AMH. All laboratory measurements to be repeated at 3 and 6 months postoperative. The blood sample taken was $10 \mathrm{~cm}^{2}$ and it was centrifuged and the serum was kept frozen in (-80 degrees Celsius). The laboratory measurements were done after finishing all samples collection.

Laparoscopic ovarian drilling (LOD) was done according to the recommendations of the world laparoscopy hospital An insulated puncture needle is introduced through the epsilateral part and 6-10 puncture points are made through the ovarian capsule in the antimesentric surface using electrocautery and the same procedure applied to the other ovary, A monopolar electrocautery current at 30 Watt power is used for 4 seconds (720-1200J per ovary). Each puncture is about $4 \mathrm{~mm}$ in diameter and 6-8 $\mathrm{mm}$ in depth and No coagulation to be done within $10 \mathrm{~mm}$ of the hilum to avoid bleeding or permanent reduction of the ovarian blood supply ${ }^{[15]}$ (Figures 1-5).

The amount of power applied on each ovary in joules $(\mathrm{J})$ is calculated by multiplying (number of punctures $\mathrm{x}$ time in seconds per puncture $\mathrm{x}$ power of current in watts $)^{[14 ; 16]}$. 


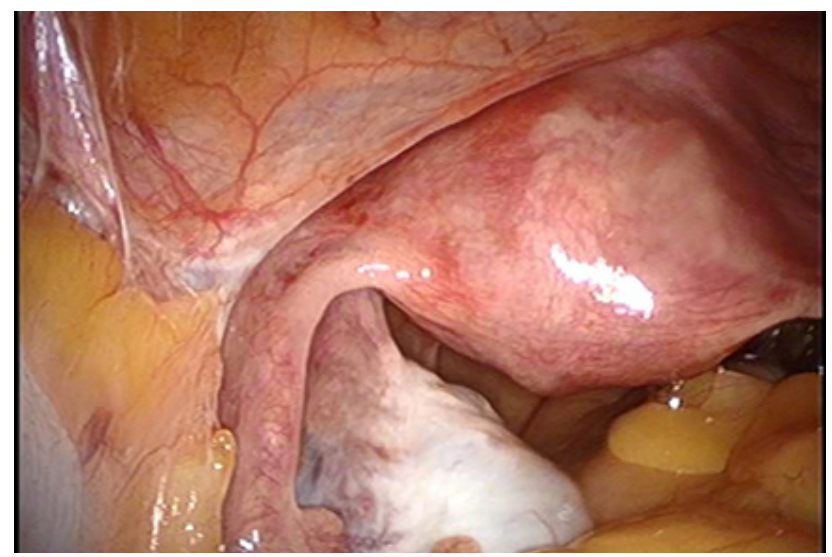

Fig. 1: using uterine manipulator to visualize the ovary.

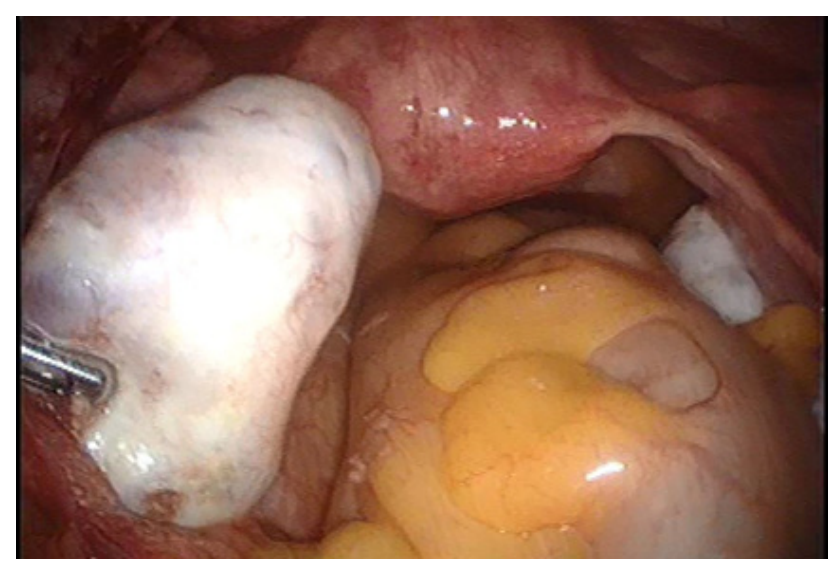

Fig. 2: grasping the ovary.

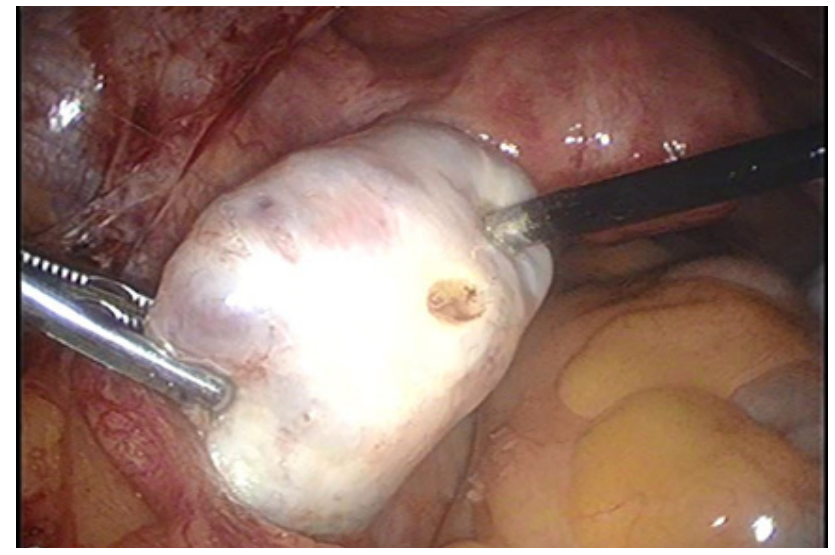

Fig. 3: drilling the ovary in the antihilar border.

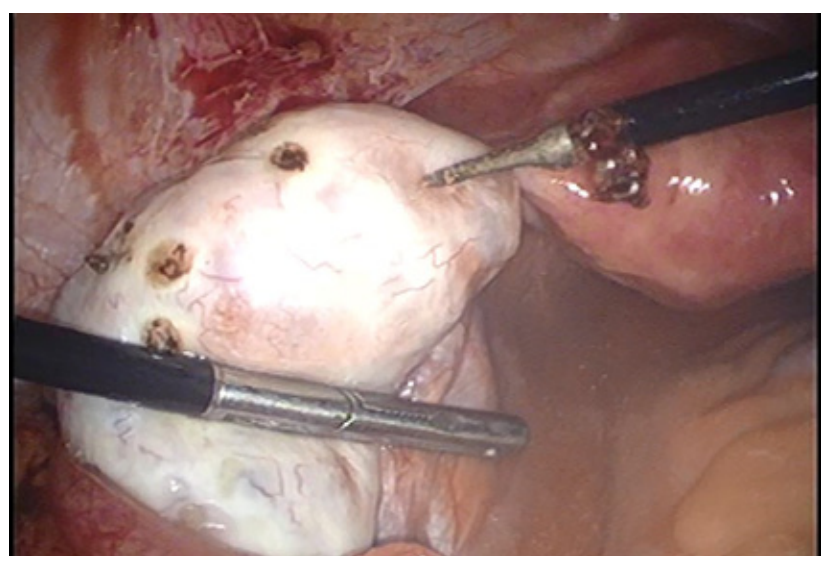

Fig. 4: number of punctures depends on the ovarian size.

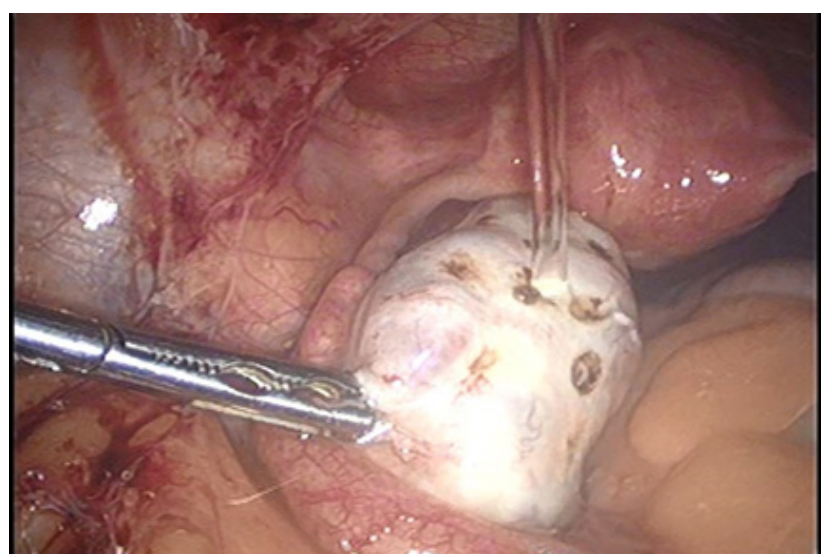

Fig. 5: cooling the ovary.

Biochemical pregnancy was reported and the 8 cases which got pregnant within 3 months postoperative were excluded from the study and 6 pregnancies occurred within another 3 months and the patients were included in the study. Comparison was done between the cases that got pregnant and the cases that did not conceive in the aspects of the same ovarian reserve parameters before the operation and after 3 months.

\section{STATISTICAL ANALYSIS}

Data entry and statistical analyses were performed using SPSS (statistical package of social sciences) version 21 (SPSS Inc., Chicago, IL, USA) ${ }^{[17,18]}$. Categorical data were expressed in number and percentage. Continuous normally distributed data were expressed in mean and standard deviation. The quantitative data were examined by Kolmogrov Smirnov test for normality of data. 
Independent sample $\mathrm{t}$ test (student $\mathrm{t}$ test) was used for continuous normally distributed data. Statistical significance was considered when probability $P$ value was less than or equal to 0.05 .

\section{RESULTS}

In our study, the included women $(\mathrm{n}=40)$ had a history infertility, $\mathrm{n}=31(77.5 \%)$ with primary infertility and $n=9(22.5 \%)$ with secondary infertility. The initial characteristics of included women were that they had a mean age of $31.2 \pm 4.04$ years and the mean body mass index (BMI) was $30.7 \pm 3.75 \mathrm{~kg} / \mathrm{m}^{2}$.

There was a significant reduction in the AMH level, LH/FSH Ratio \& Inhibin B after laparoscopic ovarian drilling at 3 and 6 months (Table 1).

Within the first 3 months after LOD, 8 patients conceived. Then, 6 more patients conceived in the next 3 months. Thus, the original total number of patients who conceived was 14 out of 48 cases (29.16\%), including the 8 patients who got pregnant within the first 3 months after the LOD.
After excluding the 8 cases, 34 patients out of 40 did not get pregnant. There was insignificant difference between both groups regarding age, BMI and years of infertility. The patients who got pregnant had a mean age of $30.1 \pm 3.8$ years, the mean BMI was $30.6 \pm 5.2 \mathrm{~kg} / \mathrm{m}^{2}$ and the mean Infertility years were $5 \pm 2.3$ years, while the patients who did not get pregnant had a mean age of $31.4 \pm 4.1$ years, the mean BMI was $30.7 \pm 3.5 \mathrm{~kg} / \mathrm{m}^{2}$ and the mean Infertility years were $5.1 \pm 2.4$ years, respectively (Table 2 ).

There was significant lower AMH levels in patients who got pregnant compared to those who did not get pregnant before laparoscopic ovarian drilling $(P=0.004)$ and after 3 months postoperatively $(P=0.003)$. There was significant lower LH/FSH ratio in patients who got pregnant compared to those who did not get pregnant before laparoscopic ovarian drilling $(P=0.002)$ and after 3 months postoperatively $(P=0.004)$. There was insignificant difference in inhibin B level in patients who got pregnant compared to those who did not get pregnant before laparoscopic ovarian drilling $(P=0.954)$ and after 3 months postoperative $(P=0.582)$ (Table 2$)$.

Table 1: ovarian reserve before and after laparoscopic ovarian drilling at 3 and 6 months: This table shows significant reduction in ovarian reserve parameters (AHM, LH/FSH Ratio, Inhibin B) after laparoscopic ovarian drilling at 3 and 6 months

\begin{tabular}{|c|c|c|c|c|c|c|}
\hline \multirow{2}{*}{ ovarian reserve } & \multicolumn{3}{|c|}{ laparoscopic ovarian drilling } & \multirow{2}{*}{$\mathrm{P} 1$} & \multirow{2}{*}{$\mathrm{P} 2$} & \multirow{2}{*}{ P3 } \\
\hline & Before & After 3 months & After 6 months & & & \\
\hline $\mathrm{AHM}(\mathrm{ng} / \mathrm{ml})$ mean $\pm \mathrm{SD}$ & $8.07 \pm 1.49$ & $6.1 \pm 1.4$ & $5.2 \pm 1.1$ & $0.001^{*}$ & $0.002^{*}$ & $0.002^{*}$ \\
\hline $\mathrm{LH} / \mathrm{FSH}$ Ratio mean $\pm \mathrm{SD}$ & $2.8 \pm 0.7$ & $1.8 \pm 0.6$ & $1.4 \pm 0.5$ & $0.003^{*}$ & $0.001^{*}$ & $0.001^{*}$ \\
\hline Inhibin $\mathrm{B}(\mathrm{pg} / \mathrm{ml})$ mean $\pm \mathrm{SD}$ & $52.5 \pm 3.68$ & $49.03 \pm 3.4$ & $45.7 \pm 3.6$ & $0.003^{*}$ & $0.002^{*}$ & $0.004^{*}$ \\
\hline
\end{tabular}

P1 compare between laparoscopic ovarian drilling before and after 3 months

$P 2$ compare between laparoscopic ovarian drilling before and after 6 months

P3compare between laparoscopic ovarian drilling after 3 and 6 months

Table 2: comparison of demographic data \& ovarian reserve parameters between patients who got pregnant compared to who did not conceive.

\begin{tabular}{|c|c|c|c|}
\hline Variable & $\begin{array}{c}\text { got pregnant } \\
n=6\end{array}$ & $\begin{array}{l}\text { did not conceive } \\
n=34\end{array}$ & $\mathrm{p}$ \\
\hline Age (years) mean $\pm \mathrm{SD}$ & $30.1 \pm 3.8$ & $31.4 \pm 4.1$ & 0.494 \\
\hline BMI $\left(\mathrm{kg} / \mathrm{m}^{2}\right)$ mean $\pm \mathrm{SD}$ & $30.6 \pm 5.2$ & $30.7 \pm 3.5$ & 0.968 \\
\hline Infertility years mean \pm SD & $5 \pm 2.3$ & $5.1 \pm 2.4$ & 0.978 \\
\hline $\mathrm{AMH} 0(\mathrm{ng} / \mathrm{ml})$ mean $\pm \mathrm{SD}$ & $6.9 \pm 1.4$ & $8.2 \pm 1.4$ & $0.004 *$ \\
\hline AMH $3(\mathrm{ng} / \mathrm{ml})$ mean $\pm \mathrm{SD}$ & $5.1 \pm 1.1$ & $6.3 \pm 1.4$ & $0.003 *$ \\
\hline $\mathrm{LH} / \mathrm{FSH} 0$ mean $\pm \mathrm{SD}$ & $2.04 \pm 0.5$ & $3.02 \pm 0.6$ & $0.002 *$ \\
\hline LH/FSH 3 mean \pm SD & $1.15 \pm 0.2$ & $1.93 \pm 0.6$ & $0.004 *$ \\
\hline inhibin B $0(\mathrm{pg} / \mathrm{ml})$ mean \pm SD & $52.5 \pm 2.2$ & $52.6 \pm 3.9$ & 0.954 \\
\hline inhibin B $3(\mathrm{pg} / \mathrm{ml})$ mean \pm SD & $48.3 \pm 2.1$ & $49.1 \pm 3.6$ & 0.582 \\
\hline
\end{tabular}




\section{DISCUSSION}

In women, serum levels of AMH correlate with the number of antral follicles, and both decline with age. Thus, $\mathrm{AMH}$ has become a useful clinical marker of ovarian reserve and reproductive disease in women. Its clinical utility has been expanding in scope for use in monitoring ovarian reserve, response to in vitro fertilization protocols, granulosa cell tumor recurrence, and diagnosis of ovarian diseases such as primary ovarian insufficiency and polycystic ovary syndrome (PCOS) ${ }^{[17]}$.

The mean AMH level was $8.07 \pm 1.49,6.1 \pm 1.4$ and $5.2 \pm 1.1(\mathrm{ng} / \mathrm{ml})$ preoperative, after 3 and 6 months postoperative respectively. The mean LH/FSH Ratio was $2.8 \pm 0.7, \quad 1.8 \pm 0.6$ and $1.4 \pm 0.5$ preoperative, after 3 and 6 months postoperative respectively. The mean Inhibin B level was $52.5 \pm 3.68,49.03 \pm 3.4$ and $45.7 \pm 3.6$ $(\mathrm{pg} / \mathrm{ml})$ preoperative, after 3 and 6 months postoperative respectively. There was a significant reduction in all the measured parameters of OR (AMH, LH/FSH ratio and Inhibin B) after laparoscopic ovarian drilling at 3 and 6 months.

All parameters used to assess ovarian reserve preoperatively in our study group were higher than normal. Although all parameters were reduced significantly after LOD after 3 months and 6 months postoperative, the parameters were almost normalized not reduced than normal representing the merits of using adjusted current doses intraoperative in preserving the ovarian reserve over the use of fixed doses.

In Salem et al. study, which was consistent with our study in terms of effect of LOD on AMH and LH/FSH ratio, $\mathrm{AMH}$ level was $6.3 \pm 2.1,4.1 \pm 1.8$ and $3.9 \pm 1.51$ $(\mathrm{ng} / \mathrm{ml})$ preoperative, after 3 and 6 months postoperative respectively. Also LH/FSH Ratio was $2.45 \pm 0.7,1.35 \pm 0.4$ and $1.2 \pm 0.25$ preoperative, after 3 and 6 months postoperative respectively ${ }^{[9]}$.

The study by Saraswat et al. was comparable to our study, in terms of significant decrease in AMH levels in women with PCOS after laparoscopic ovarian drilling. The mean preoperative AMH level was 9.86 \pm 6.028 versus $6.03 \pm 3.742 \mathrm{ng} / \mathrm{ml}$ postoperative at day 2 of next cycle $(p<0001)^{[19]}$.

The study by Farzadi et al. was contradictory to our study in the aspect of the effect of LOD on AMH level. The average amount of AMH serum levels was $8.4 \pm 4.77 .5 \pm 4.5,7 \pm 4.5$, and $7.7 \pm 4.4 \mathrm{ng} / \mathrm{ml}$ $(p=0.70)$ before laparoscopic surgery and one week, 3 and 6 months after surgery, respectively ${ }^{[20]}$. However, Farzadi et al. used monopolar hook diathermy for LOD and no details were provided regarding the power setting or the duration of each puncture, thus the thermal dose used on the ovary could not be calculated.

The results in the bilateral drilling group (group III) of the study by Kandil \& Selim, were consistent with our study regarding the effect of bilateral LOD on Inhibin
B level. There was a significant decrease of inhibin B level after bilateral drilling compared with its predrilling level $(53.8 \pm 13.5$ vs $46.3 \pm 6.2 \mathrm{pg} / \mathrm{ml} ; \mathrm{P}=0$. 031). No significant changes occurred in inhibin $\mathrm{B}$ level after unilateral drilling or clomiphene citrate ${ }^{[21]}$.

In the study by Amer et al, although LH/FSH Ratio was reduced significantly from $2.6 \pm 0.2$ to $1.9 \pm 0.2$ $(p<0.001)$ after LOD which was consistent with our study, However, no statistically significant change of plasma concentrations of inhibin B from the pre-operative values in the overall group of 50 women with PCOS $[110.0$ $\mathrm{pg} / \mathrm{ml}$ (range 19.0-567.0 $\mathrm{pg} / \mathrm{ml}$ ) versus $106.0 \mathrm{pg} / \mathrm{ml}$ (range $6.7-284.0 \mathrm{pg} / \mathrm{ml}$ )]. This is not consistent with the present study. The overall lower preoperative and postoperative Inhibin B levels in our study were possibly due to confounding effect of obesity on inhibin B concentrations. In other words, although PCOS women might oversecrete inhibin $\mathrm{B}$ as a result of increased numbers of small antral follicles, this effect is counteracted by the increased BMI which occurs in a large number of PCOS women. This balancing effect would not occur in non-obese PCOS women. The difference in BMI and inhibin B level between both studies may explain the difference in the effect of LOD on inhibin B levels in both studies $^{[22]}$.

Eight cases of our studied patients got pregnant within the first three months after LOD and six cases got pregnant after three months. The total number of cases that got pregnant was 14 out of 48 cases before excluding the 8 cases that got pregnant before 3 months $(29.16 \%)$. After excluding the 8 cases that conceived within the first 3 months, 34 patients out of 40 did not get pregnant, The pregnancy rates were not related to the preoperative levels of Inhibin B, but they were significantly related to the preoperative AMH levels and LH/FSH ratio when comparing the cases that got pregnant with the cases who did not conceive postoperatively. The cases who got pregnant had lower AMH levels and lower LH/FSH ratios preoperative than the cases who did not get pregnant, however; all cases had elevated AMH levels and LH/FSH ratios than normal population.

The mean preoperative AMH level before the operation was $6.9 \pm 1.4 \mathrm{ng} / \mathrm{ml}$ and $8.2 \pm 1.4 \mathrm{ng} / \mathrm{ml}$ for the patients who got pregnant and those who did not get pregnant respectively. While the mean AMH level after 3 months of the operation was $5.1 \pm 1.1 \mathrm{ng} / \mathrm{ml}$ versus $6.3 \pm 1.4 \mathrm{ng} /$ $\mathrm{ml}$ for the patients who got pregnant and those who did not get pregnant respectively. There was significant lower preoperative $\mathrm{AMH}$ level in patients who got pregnant compared to those who did not get pregnant before laparoscopic ovarian drilling $(p=0.004)$ and also the postoperative AMH level after 3 months of the operation was significantly lower in the patients who got pregnant compared to the patients who did not conceive $(p=0.003)$.

The study by Saraswat et al. was inconsistent with our study regarding the outcomes of pregnancy versus pre and 
post LOD AMH levels which was also looked into. Mean value of pre and post LOD AMH levels were found to be $11.19 \mathrm{ng} / \mathrm{ml}$ and $7.21 \mathrm{ng} / \mathrm{ml}$ respectively in women who achieved pregnancy versus $9.18 \mathrm{ng} / \mathrm{ml}$ and $6.03 \mathrm{ng} / \mathrm{ml}$ in those who did not. Though there was a significant reduction in the AMH levels post LOD both on 7th postoperative day (POD) and on 2nd day of the next cycle, statistical tests did not show any significant correlation between these $\mathrm{AMH}$ values in the patients who achieved pregnancy as compared with those who did not.

However, the patients who had higher pre LOD AMH levels were found to have better chances of pregnancy in this study suggesting that the subgroup of clomiphene resistant PCOS patients with high AMH levels may benefit more from LOD as compared to those in whom AMH is normal or only marginally raised ${ }^{[19]}$. The difference of results between this study and our study may be attributed to the different patients' types as our patients were all PCO phenotype A according to Carmina classification of types of PCO patients ${ }^{[13]}$.

The mean preoperative LH/FSH ratios were $2.04 \pm 0.5$ and $3.02 \pm 0.6$ for the patients who got pregnant and those who did not get pregnant respectively. While the mean LH/ FSH ratios after 3 months of the operation were $1.15 \pm 0.2$ and $1.93 \pm 0.6$ for the patients who got pregnant and those who did not get pregnant respectively. There was significant lower preoperative LH/FSH ratio in patients who got pregnant compared to those who did not get pregnant $(P=0.002)$ and also the postoperative Inhibin B level after 3 months of the operation was significantly lower in the patients who got pregnant compared to the patients who did not conceive $(p=0.004)$.

The mean inhibin B level before the operation was $52.5 \pm 2.2 \mathrm{pg} / \mathrm{ml}$ and $52.6 \pm 3.9 \mathrm{pg} / \mathrm{ml}$ for the patients who got pregnant and those who did not get pregnant respectively. While the mean inhibin B level after 3 months of the operation was $48.3 \pm 2.1 \mathrm{pg} / \mathrm{ml}$ and $49.1 \pm 3.6 \mathrm{pg} / \mathrm{ml}$ for the patients who got pregnant and those who did not get pregnant respectively. There was insignificant difference in inhibin B level in patients who got pregnant compared to those who did not get pregnant before laparoscopic ovarian drilling $(P=0.954)$ and after 3 months postoperative $(P=0.582)$

The results related to pregnancy in the study by Rezk et al. were inconsistent with our results regarding pregnancy rate in relation to patients' characteristics which were: The higher rates was observed in younger patients $(<25$ years), with lower BMI $(<25$ years) and with shorter duration of infertility ( $<3$ years) $(p<0.05)$. Although the ovulation and pregnancy rates at 3 months periods were higher in the bilateral ovarian drilling (BLOD) group, it did not reach to a significant difference $(p>0.05)$. But was significant at 6 -month period $(p<0.05)$. However, higher rates of pregnancy were observed with lower preoperative lower AMH levels $(<5 \mathrm{ng} / \mathrm{ml})(p<0.05)$ which is consistent with our findings ${ }^{[23]}$.
The difference of results between this study and our study regarding the effect of the demographic data (age, BMI and duration of infertility) on the pregnancy rates may be due to the homogeneity of the demographic data of our patients. Our patients are all with high BMI while the differences in age and years of infertility are insignificant amongst them.

\section{CONCLUSION}

Although all parameters of ovarian reserve were reduced significantly after LOD, Pregnancy rates were significantly related to the preoperative AMH levels \& LH/FSH ratio when comparing the cases that got pregnant to the cases who did not conceive postoperatively in patients of polycystic ovary syndrome (PCOS). Therefore, AMH measurement could be a useful tool in assessing and predicting the results of LOD on PCOS patients concerning the pregnancy results after the operation not only in assessment of ovarian reserve after the drilling.

\section{CONFLICT OF INTERESTS}

There are no conflict of intersts.

\section{REFERENCES}

1. Merhi Z, Kandaraki EA \& Diamanti-Kandarakis E (2019): Implications and Future Perspectives of AGEs in PCOS Pathophysiology. Trends Endocrinol Metab; 30(3):150-62.

2. Luo H, Han Y, Liu J \& Zhang Y (2019): Identification of microRNAs in granulosa cells from patients with different levels of ovarian reserve function and the potential regulatory function of miR-23a in granulosa cell apoptosis. Gene; 686:250-60.

3. Uludag SZ, Ozgun MT, Dolanbay M, Altun O, Aygen EM and Sahin Y (2017): Evaluating the Association of Ovarian Reserve with Age in Women with Polycystic Ovary Syndrome. Glob J Fertil Res 2(1):004-8.

4. Abbasi S, Siddiqua SF, Alam MNA and Jesmin S (2018): Evaluation of Anti- Müllerian Hormone level as a marker of Ovarian Reserve and correlate it with Laparoscopic Surgery of Pelvic Endometriosis in Subfertile Patients. BIRDEM Med J; 8(1): 30-4.

5. Iwase A, Osuka S, Goto M, Murase T, Nakamura T, Takikawa S and Kikkawa F (2018): Clinical application of serum anti-Müllerian hormone as an ovarian reserve marker: A review of recent studies. J. Obstet. Gynaecol. Res; 44(6): 998- 1006.

6. Strauss III J \& Williams CJ (2019): Ovarian Life Cycle. In Strauss \& Barbieri: Yen \& Jaffe's Reproductive Endocrinology, $8^{\text {th }}$ ed. Elsevier, Inc.; 8:167-205. 
7. Al-Hussaini TK, Zakhera MS, Abdel-Aleem M and Abbas AM (2017): Premature ovarian failure/ dysfunction following surgical treatment of polycystic ovarian syndrome: A case series. Middle East Fertility Society Journal 22: 233-5.

8. Teede HJ, Misso ML, Costello MF, Dokras A, Laven J, Moran L, Piltonen T, Norman RJ, on behalf of the International PCOS Network (2018): Recommendations from the international evidencebased guideline for the assessment and management of polycystic ovary syndrome. Hum Reprod; $33: 1602-18$

9. Salem MN, Ahmed SR, Abbas AM, Salem AN and Sabala A El M (2017): Short term effects of laparoscopic ovarian drilling in clomiphene citrate resistant patients with polycystic ovary syndrome. Middle East Fertil Soc J; 22(4): 290-4.

10. Garg D \& Tal R (2016): The role of AMH in the pathophysiology of polycystic ovarian syndrome. Reproductive BioMedicine Online; 33(1):15-28.

11. Balen AH (1999): Polycystic ovary syndrome: medical or surgical treatment? In: Evidence based fertility treatment. Templton A. Cooke I and O'Brin PMS RCOG. bl P: 157.

12. Rotterdam ESHRE/ASRM-Sponsored PCOS Consensus Workshop Group. (2004): Revised 2003 consensus on diagnostic criteria and long-term health risks related to polycystic ovary syndrome.Fertil Steril; 81:19-25.

13. Carmina E (2018): PCOS Phenotypes: Impact on Fertility. In Palomba S: Infertility in Women with Polycystic Ovary Syndrome. Pathogenesis and Management. Springer; 7:81-8.

14. Elmashad AI (2011): Impact of laparoscopic ovarian drilling on anti-Müllerian hormone levels and ovarian stromal blood flow using three-dimensional power Doppler in women with anovulatory polycystic ovary syndrome Fertil Steril ; 95(7):2342-6.
15. Mishra RK (2009): Laparoscopic Ovarian Surgery. In Mishra RK. Textbook of practical laparoscopic surgery. $2^{\text {nd }}$ ed. Jaypee Brothers Medical Publishers, New Delhi; 28:370-80.

16. Amer SA, Li TC \& Ledger WL (2009): The value of measuring antiMüllerian hormone in women with anovulatory polycystic ovary syndrome undergoing laparoscopic ovarian diathermy. Human Reproduction 24: $2760-6$.

17. Dean F (2006): Statistical methods in scientific researches. Europian Journal of Scientific Research; 14(3).

18. Rodriguez A, Matzuk MM \& Pangas SA (2019): Growth Factors and Reproduction. In Strauss \& Barbieri: Yen \& Jaffe's Reproductive Endocrinology, $8^{\text {th }}$ ed. Elsevier, Inc.; 6:132-48.

19. Saraswat M, Jose T, Rajput M and Siddique N (2017): Impact of laparoscopic ovarian drilling on antimullerian hormone levels in women with clomiphene resistant polycystic ovary syndrome. Indian Journal of Obstetrics and Gynecology Research; 4(3):297-300.

20. Farzadi L, Nouri M, Ghojazadeh M, Mohiti M \& Aghadavod E (2012): Evaluation of ovarian reserve after laparoscopic surgery in patients with polycystic ovary syndrome, BioImpacts; 2(3):167-70.

21. Kandil M \& Selim M (2005): Hormonal and sonographic assessment of ovarian reserve before and after laparoscopic ovarian drilling in polycystic ovary syndrome. BJOG; 112(10):1427-30.

22. Amer SA, Laird S, Ledger WL and Li TC (2007): Effect of laparoscopic ovarian diathermy on circulating inhibin B in women with anovulatory polycystic ovary syndrome. Human Reproduction; 22(2):389-94.

23. Rezk M, Sayyed T, and Saleh S (2016): Impact of unilateral versus bilateral laparoscopic ovarian drilling on ovarian reserve and pregnancy rate: a randomized clinical trial. Gynecological Endocrinology; 32: 99-402. 